\title{
As leis do cosmos e a liberdade do homem Giovanni Pico Della Mirandola e Leon Batista Alberti
}

\author{
Jonathan Molinari
}

\section{SciELO Books / SciELO Livros / SciELO Libros}

MOLINARI, J. As leis do cosmos e a liberdade do homem: Giovanni Pico Della Mirandola e Leon Batista Alberti. In: PINTO, F.M., and BENEVENUTO, F., comps. Filosofia, política e cosmologia: ensaios sobre o renascimento [online]. São Bernardo do Campo, SP: Editora UFABC, 2017, pp. 33-57. ISBN: 978-85-68576-93-9. https://doi.org/10.7476/9788568576939.0004.

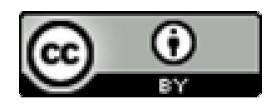

All the contents of this work, except where otherwise noted, is licensed under a Creative Commons Attribution 4.0 International license.

Todo o conteúdo deste trabalho, exceto quando houver ressalva, é publicado sob a licença Creative Commons Atribição 4.0.

Todo el contenido de esta obra, excepto donde se indique lo contrario, está bajo licencia de la licencia $\underline{\text { Creative }}$ Commons Reconocimento 4.0 . 
Mestre em Letras e Filosofia pela Università degli Studi di Bologna (2008) e doutor em filosofia pelo Istituto Italiano di Scienze Umane - Scuola Normale Superiore di Pisa (2012). Concluiu o pós-doutorado (2016) em filosofia da renascença italiana na Universidade de São Paulo (USP) tendo sido bolsista da FAPESP. Também em 2016 publicou o livro intitulado: Libertà e discordia: Pletone, Bessarione, Pico della Mirandola, pela editora Il Mulino(Bologna). Atua principalmente nos seguintes temas: relação entre filosofia e literatura na renascença italiana, direitos humanos e dignidade humana no debate historiográfico contemporâneo sobre o humanismo, problema da linguagem e formas simbólicas na cultura da Europa moderna (século XIII-XVI). 


\section{AS LEIS DO COSMOS E A LIBERDADE DO HOMEM: GIOVANNI PICO DELLA MIRANDOLA E LEON BATISTA ALBERTI ${ }^{1}$}

Jonathan Molinari ${ }^{2}$

\section{Pico e Alberti}

Eugenio Garin (1975, p. 145), no seu ensaio sobre Leon Battista Alberti, publicado em 1975, enfatizava como "estranhamente ninguém havia notado que algumas décadas antes que Giovanni Pico della Mirandola compusesse a famosa abertura hermética da Oratio de Hominis Dignitate, Alberti já havia escrito a paródia”. Segundo Annarita Angelini (2007, p. 64), "contraste, crise, ambivalência, impossibilidade de uma solução pacificadora, acompanha toda a reflexão de Alberti” e

\footnotetext{
${ }^{1}$ Pesquisa realizada graças a uma bolsa de pós-doutorado da Fundação de Amparo à Pesquisa do Estado de São Paulo (FAPESP). Texto traduzido em português pela Dra. Daniela Spinelli.

${ }^{2}$ Professor de Filosofia da Universidade Federal do Pará.
} 
são elementos que confirmam claramente o caráter "invertido" da antropologia albertiana, a respeito da imagem do "divino camaleão", do célebre Discurso de Pico. Os tons fortemente pessimistas de Alberti no Theogenius, no Momus e nas Intercenales são verdadeiramente tão distantes quanto se poderia pensar da celebração de Pico acerca da dignidade humana, e os dois autores parecem exprimir perfeitamente aquela tensão entre humanismo e anti-humanismo, sobre a qual tem insistido parte da historiografia recente. Como notou Carlos Brandão, não se trata, porém, de uma contraposição de dois momentos sucessivos do pensamento renascentista, mas de uma dialética profunda que atravessa todo o humanismo: humanismo e anti-humanismo, escreve Brandão,

[...] são polos que estão em luta permanente desde o início do Renascimento, que se tencionam reciprocamente e que não mais nos permitem ter dele a visão homogênea que predominou na historiografia herdada de Burckhardt e de Michelet (BRANDÃO, 2010, p. 150).

Aquela que pode parecer ser uma fratura irremediável entre dois aspectos antitéticos do humanismo, de uma parte o otimismo acerca da grandeza humana unida ao triunfo da vontade de potência do homem sobre a natureza, e de outra a visão trágica do homem entendido como "ponto de crise" e "momento de fratura de uma ordem", é em realidade o fundamento de uma tensão dialética mais profunda, é o sinal de uma pesquisa que combina autores muito diversos entre si e que define a urgência mais radical do humanismo italiano.

3 Cf. Garin (1972, p. 16). Ver também Angelini (2007, p. 61). 
O Alberti da obra De re aedificatoria se move em direção oposta à denúncia da inutilidade e da loucura do agir humano do Theogenius. A mesma reversão se dá entre a extraordinária celebração do ser humano na Oratio de Giovanni Pico e as observações que o filósofo faz nas suas Disputationes, sobretudo, quando pensa a humanidade como um bando de "homúnculos inclinados para o chão" (PICO, 1946, p. 444). A propósito da obra de Alberti, Eugenio Garin (1975, p. 153) escreveu que nela "várias perspectivas coexistem na sua contraditoriedade, porque contraditória, e cheia de loucura, é a inteira realidade", e é no fundo o mesmo esforço que em muitos aspectos se encontra também nas obras de um pensador como Pico. A reflexão sobre a relação entre cosmologia, ética e natureza em Giovanni Pico e Leon Battista Alberti se mantém de fato sobre este espaço, de dois pensadores certamente muito diferentes entre si, mas unidos por uma ideia de filosofia que não renuncia jamais a interrogar-se sobre as contradições mais profundas do homem e da natureza: em ambos age aquela tensão entre procura de significado e desilusão, entre a vontade de saber e a consciência do limite humano, entre confiança no homem e consciência de sua fraqueza, que caracteriza os momentos mais altos da filosofia do Quattrocento.

\section{Definição da ordem}

O problema que está na base da relação entre cosmologia, ética e natureza em grande parte da filosofia do Quattrocento, pode ser afrontado a partir do conceito de ordem: existe uma ordem in natura que transforma a matéria desordenada em um cosmo harmônico e ordenado? Qual é o 
arquiteto - se existe - que projetou a perfeita máquina do cosmo? E se esta ordem existe, o homem tem a possibilidade de compreendê-la e de adequar a sua própria ação moral às leis naturais das coisas?

Para Leon Battista Alberti, a natureza é em si sempre "absolutamente perfeita", enquanto na variedade dos tons da obra albertiana esta ideia nunca muda, mesmo que com acentos diversos. Para vingar-se dos deuses, Momo se fez primeiro poeta e depois filósofo para ensinar que "todos os seres animados têm uma única divindade em comum, a Natureza, que tem a missão precisa de governar não apenas os homens, mas todos os outros animais" (ALBERTI, 1986, p. 76). Além disso, "todas as coisas criadas pela Natureza têm uma função bem precisa, que são boas ou ruins do ponto de vista humano" (Ibidem), mas a ordem da Natureza é perfeita e superior ao juízo do homem, e de fato - prossegue Alberti - "[...] muitas coisas que o preconceito comum entende por defeitos, não o são de fato" (Ibidem). Confrontada com um texto muito diferente pelos tons e cenários, a ideia de fundo não parece mudar: no De Iciarchia (ALBERTI, 2014, Livro III) “é per natura que o homem nasce capaz de reconhecer as razões e as ordens das coisas" e é sempre a Natureza que define "aquilo que o homem deve temer ou fugir" (Ibidem). Neste ponto não existe nenhuma fratura entre o indivíduo e a Natureza: a ordem das coisas compreende em si o homem como uma das tantas partes do grande desenho do mundo. A Natureza "jamais errou e jamais errará" - escreve Alberti - por isso forneceu ao homem intelecto, razão e a linguagem ${ }^{4}$, de modo que pudesse inserir-se

\footnotetext{
${ }^{4}$ De acordo com Alberti "nunca, em coisa nenhuma a natureza em si errou, e jamais errará" (Ivi, Livro I). Sobre o por que a natureza concedeu a palavra aos homens, Alberti escreveu que: "Nós vemos comuns aos outros animais as suas vozes dadas pela natureza para algum fim, com alguma razão. Seria uma injuria
} 
no projeto do cosmo como um ser "útil a si mesmo, e não menos aos outros" ${ }^{5}$. Tanto que se considerarmos o homem como uma brincadeira da Natureza, se atribuírmos a ele a possibilidade de agir de maneira virtuosa - em conformidade com os ditames naturais da razão - resta inalterada a ideia de uma ordem natural por si só justa e infalível. No Theogenius, a ideia de uma ordem estável e imprescindível da Natureza se impõe com igual clareza: "cada um segue a sua ordem e progresso da natureza: nada pode variar, nada pode sair da sua imposta e escrita lei" (ALBERTI, 2014, Theogenius, Livro I). Porém, paradoxalmente, o elemento de estabilidade no qual se explica a lei natural é quanto mais instável seja, é o movimento perpétuo de todas as coisas, é o eterno fluxo de se tornar: "a todas as outras coisas mortais - escreve Alberti no Theogenius - vemos ser fatal e escrita a ordem da natureza que está sempre em movimento, e em desigual sucesso vemos os céus inovarem continuamente a sua variedade”, uma variedade não distante da hipótese que, no Momus, vai até a ideia de "infinitos mundos que se formam e se desgastam continuamente",

se às bestas fosse concedida a explicação dos seus conceitos com mais razão que aos homens. Dizem que o cão, abana por fome, ulula por desejo, grunhe de raiva, murmura por amor. Não é acreditável que em nós existam palavras sem razão e ótima finalidade, quanto somos diferentes e superiores de todo o resto os outros animais. O falar por sua natureza mostra a ordem das coisas do passado, e rende a razão para o presente; e diz-se que o falar é o vinculo da sociedade entre os homens, perguntando para apreender e dizendo para explicar" (tradução nossa, Livro II).

5 ALBERTI. De Iciarchia, Livro I: "a natureza não deu ao homem tanta proeza de engenho, inteligência e razão, para que apodrecesse no ócio e na preguiça. $O$ homem nasce para ser útil a si mesmo, e não menos para os outros. A primeira e própria utilidade nossa será fazer uso das forças da nossa alma em virtudes, para reconhecer as razões e ordem das coisas, e, em seguida, para a reverência à Deus" (tradução nossa). 
"mundos de formas variadas" regidos apenas pela ordem da eterna mudança ${ }^{6}$.

A ideia de Natureza de Pico é bem diversa daquela de Alberti: ao mundo físico, não pode pertencer nenhuma perfeição verdadeira, porque perfeito é somente o mundo intangível, perfeitas são as ideias que governam o todo, e a Natureza deste mundo não é outra coisa que um equilíbrio instável das partes. Isto não impede Pico de pensar em uma ordem física regida de qualquer modo por regras precisas, ao contrário, é própria a imperfeição da Natureza, a conditio sine qua non da sua beleza. No Heptaplus o mundo físico deriva de "uma comum mistura, de todo modo regulada por normas" (PICO, 2004, p. 217), de uma união de matéria e forma provisória e temporal, mas ordenada e não casual. É a mesma lógica segundo a qual, no Commento, Pico define a Natureza citando Heráclito e Homero: "dizia Heráclito que a guerra é geradora das coisas, e em Homero, quem amaldiçoa a restrição, é dito ter blasfemado a natureza" (Ibidem, p. 495). A ideia de Natureza como eterna luta entre os componentes que formam os corpos não exprime apenas a eterna mudança e a degeneração do mundo físico; ao invés disso é a premissa necessária para pensar em uma "mistura proporcional" entre as partes, e portanto uma "inimizade amiga" que assinala a passagem da matéria sem forma a um cosmo organizado: "a beleza inclui em si qualquer imperfeição" (Ibidem, p. 495) - escreve Pico - e neste sentido, "a beleza propriamente dita pertence somente ao mundo humano e à natureza, mas não a Deus". A "discórdia concorde" entre as partes, porém, não pode

\footnotetext{
${ }^{6}$ Sobre a leitura de Giordano Bruno destas páginas do Momo, Cf. Garin (1975, p. 140-141).
} 
realizar equilíbrios provisórios: as mesmas regras que estruturam o mundo físico o configuram como perene "vicissitude de vida e de morte" (Idem, p. 185). É aqui, então, que a ordem da Natureza, entendida como perfeição absoluta em Alberti e como harmonia que nasce do conflito em Pico, se encontra com o problema do tempo. O tempo da Natureza, em Alberti, indica a hipótese de um infinito alternar-se de mundos diversos, e em Pico indica os riscos dos equilíbrios a ponto de serem destruídos. Mas também o tempo do homem, tão breve para compreender a ordem da Natureza e tão incerto para evitar os riscos do acaso e da liberdade.

\section{Destruição da ordem}

Qual é o lugar e a função do homem frente à Natureza "absolutamente perfeita" de Alberti, ou frente ao frágil equilíbrio da "concórdia discórdia" da qual trata Pico? E em que modo o homem pode compreender a ordem perfeita da Natureza ou até mesmo modificá-la e destruí-la? Do tempo humano nasce o conflito entre Natureza e vontade, entre a ordem do cosmo e a liberdade. O arquiteto do De re aedificatoria, l'"omicciuolo" do Theogenius, o "divino camaleão" do Oratio e o "homúnculos" das Disputationes, todos têm uma coisa em comum: estão de frente ao mesmo abismo, e este abismo é o tempo. Alberti e Pico citam os versos extraordinários de Píndaro: os homens são "criaturas de um dia", epàmeroi, sonhos de uma sombra ${ }^{7}$. Pico (2004, p. 481) os usa, no seu Commento, para descrever a condição terrena do homem, e Alberti os

7 PINDARO. Pitica VIII, p. 92 ss. 
transforma em uma extraordinária página do Theogenius: "quase sombra de um sonho" é o homem (ALBERTI, 2014, Theogenius, Livro II). A consciência da temporalidade transforma o homem em sombra de si mesmo, na inconsistência do reflexo de um sonho, e é precisamente essa transfiguração do humano colocado de frente da própria temporalidade que rende todo incerto e indefinido. Incerta e indefinida é a história do pensamento humano, que para Pico fica sempre escondida dentro dos véus dos antigos mitos, dentro das palavras dos poetas, dentro da complexa simbologia da cabala e dos textos sacros. Incerto é o conhecimento que o homem pode ter de si mesmo, de uma criatura que não possui uma existência definível, mas que contém em si um abismo indefinido de todas as possibilidades de ser. Enfim, é incerta a consciência que o homem tem da Natureza, porque os tempos da Natureza superam a capacidade da racionalidade humana e das suas linguagens. "Cada indagação - escreve Pico (1946, vol. 1, p. 103) - de qualquer fenômeno se ocupa, conhece de certa forma, do verossímil, e não da verdade", e deste modo, o filósofo de Pico não é, de fato, distante do arquiteto de Alberti: colocado em um mundo de aparências, é o sujeito que interpreta a realidade construindo relações verossímeis entre os fenômenos ${ }^{8}$. O filósofo o faz comparando todas as tradições filosóficas para reinterpretá-las e recolocá-las no interior de um quadro mais geral, a "concórdia philosophorum", na qual os elementos de cada uma se harmonizam em uma "nova filosofia", entendida como reformulação e recomposição do passado. $\mathrm{O}$ arquiteto

\footnotetext{
${ }^{8}$ Este é o significado também do parágrafo 18 do De Pictura, onde Alberti trata da "comparazione". Não existe uma realidade unívoca para representar, mas é o artista a instaurar entre os vários elementos da composição, o tipo de relação mais funcional à representação.
} 
de Alberti, do mesmo modo, deve elaborar uma estratégia para remodelar a relação entre os elementos, e não cria uma nova ordem do nada, mas reelabora e reformula as proporções e as relações de força entre as partes (ANGELINI, 2007, p. 64). Em Pico, a condição que permite ao sujeito seguir esta estrada é a liberdade. E é propriamente a partir da instância ético-moral da liberdade que Pico coloca radicalmente em discussão a versão aristotélica-ptolemaica do cosmo.

Para reivindicar a liberdade do homem de uma influência dos planetas e da astrologia, Pico sustenta que o homem não pode ser escravo das influências celestes, porque as influências astrais não são causas universais e os únicos verdadeiramente observáveis são relacionados apenas à luz, ao movimento e ao calor, todos, elementos que certamente influenciam o mundo físico, mas que de nenhum modo podem colocar em discussão o livre arbítrio'. Em segundo lugar, Pico desenvolve um problema de método: se também existissem outros elementos celestes capazes de agir sobre a realidade humana, a astrologia não teria os instrumentos para prevê-los ${ }^{10}$ ? O raciocínio de Pico sobre o método está estreitamente ligado à perspectiva histórica dentro da qual se coloca toda a sua

\footnotetext{
9 "Id quod ita tractabitur a nobis, ut hoc quidem libro defendamus agere caelum in nos tantum motu et lumine; praeter haec frustra occultiores afflatus alios cogitari; tum a lumine illo siderum et motu, non aliud communicari materiae patienti quam motum, lucem et calorem" (PICO, 1946, vol. I, p. 176-178).

${ }_{10}$ A astrologia adivinhadora não é baseada nos únicos instrumentos que os homens têm a disposição para conhecer a natureza: o sentido e a razão. A astrologia não pode ser demonstrada neque sensu neque ratione (PICO, 1946, vol. I, p. 276), porque isso exigiria experimentos impossíveis, "algo infinito, não reduzível nem a um método, nem a qualquer arte” (Idem, p. 464). Os argumentos dos astrólogos estão errados porque são baseados em uma forma de experiência que não tem "nada de congruente, de constante, de verdadeiro, de credível, de válido" (Idem p. 43). As observações dos astrólogos são feitas sem a orientação da razão, a "única força inata contra o engano" (Idem, p. 39).
} 
crítica à astrologia; e é este o elemento mais forte do discurso de Pico: a história falsifica não apenas todos os prognósticos da astrologia, mas também mina o estatuto epistemológico de cada conhecimento astronômico.

Os modernos afirmam a existência de tão numerosos e tão variados movimentos dos corpos celestes, desconhecidos como acreditam os antigos, e como eles acreditam, finalmente, capturados por uma longa e constante observação. Bem, o seu exemplo faz manifestar a possibilidade de que outros movimentos ainda estão ocultos para os astrônomos, ou pela sua lentidão, ou por sua obscuridade, ou por alguma outra razão que a posteridade saberá, um dia, por meio de observações adicionais (PICO, 1946, vol. II, p. 227) (Tradução nossa).

Os tempos e a vastidão do cosmo se chocam com os limites da observação humana e, historicamente, muitas verdades da astronomia foram destruídas porque o objeto de estudo é tal que exclui qualquer conhecimento certo. É neste sentido que Pico critica as bases da cosmologia aristotélico-ptolomaica, transformando o problema da estrutura do universo naquele das capacidades humanas de compreendê-lo, para chegar à conclusão de que nenhum sistema cosmológico elaborado por um homem poderá jamais ser exaustivo e perfeito. Depois de ter discutido as hipóteses de Ptolomeu, Giovanni di Sassonia, Haly e Leone Ebreo sobre a possibilidade de admitir oito, nove ou dez esferas, Pico conclui afirmando que "nós temos relatado todas estas hipóteses para afirmar que em tal argumento, nada se pode sustentar de certo e de inquestionável, porque cada discussão termina em posições prováveis e mutáveis" (PICO, 1946, vol. II, p. 235). O conhecimento 
humano do cosmo e da Natureza é definido como provável e mutável, não é apenas pela vastidão do objeto e a dificuldade de observação, mas também porque, quem realiza o estudo sobre o assunto, é o homem um ser constitutivamente mutável e em construção.

O homem de Pico, pleno em sua indeterminação, por um lado, é um ponto de ruptura na ordem da natureza, e, por outro, é síntese e termo de união. Posto que a natureza seja uma sucessão de equilíbrios provisórios, uma alternância de formas e misturas na qual proporções se realizam, uma beleza e uma ordem destinadas a dissolver-se e talvez a recompor-se em outras formas, o homem é o elemento que realiza o sentido deste fluir, compreendendo-o em si e fixando-o. O "divino camaleão" de Pico não tem essência fixa, caso contrário, não poderia, de nenhum modo, compreender em si uma realidade multiforme e fugaz. Como escreveu Carlos Brandão (2010, p. 161), também o homem de Alberti "não se define como uma essência fixa", mas é "um homem fragmentado, indivíduo 'em divisão', metamórfico, camaleônico". Adão e Narciso, ambos de essência indefinida e impenetrável, o primeiro, um "extraordinário escultor" de si mesmo, o outro, intencionado a "abraçar com arte aquela superfície da fonte" (ALBERTI, 2014, De Pictura \$26). Adão que pode extraviar-se nas aparências e transformar-se em besta, Narciso transformado em flor no instante em que viola o véu que separa o homem da consciência de si mesmo. É uma forma trágica de liberdade que compartilham e os condena à metamorfose: ambos devem olhar sobre o abismo da consciência de si tendo como única finalidade a ordenação e a compreensão de uma realidade que, sem o seu olhar, não teria razão de existir. 
O Adão de Pico (2004, p. 301), criado para "apreciar, amar e admirar" todo o universo, deve ser "escultor de si mesmo" e filósofo, para reunir e conectar (corrogat et counit) cada grau da realidade. Espírito e Natureza, mundo inteligível e mundo físico, pensamento e matéria, se "harmonizam" no homem "que tem em si o fundamento da sua paz"11 e que pode exprimi-la na arte: "a natureza espiritual de tudo não se pode pensar em conjunto com os corpos, senão como a arte, que está na mente do arquiteto, que conjuga o cimento, a madeira, as pedras" (PICO, 2004, p. 315). Do mesmo modo o homem que não está "em paz consigo mesmo", o homem dilacerado na divisão entre corpo e espírito - arrastado na carne como o "bruto" da Oratio - destrói a si mesmo e a harmonia que é chamado a realizar. O pecado, a violação da ordem, o prejuízo do homem ao realizar-se - como ponto de síntese entre mundo intangível e mundo físico - não acerta apenas o homem: no momento em que o homem rompe a relação com a qual compreende em si todos os graus da realidade, a ordem mesma da Natureza é violada: "nos livros dos profetas - escreve Pico - quando se reporta um comando ou um veto de Deus, se invocam ao testemunho o céu e a terra, porque, a violação da lei os ofende também" (Idem, p. 307).

Através do homem, o mundo sensível se comunica e se funde com aquele intangível e a realidade corpórea, percebida com os sentidos, reordenada pela razão e reformada pela imaginação, se transforma na forma pura da ideia ${ }^{12}$. Esta relação

\footnotetext{
11 "As coisas terrenas servem ao homem; as coisas celestes lhe dão a sua assistência, porque ele é o vinculo e o nó das coisas celestes e terrenas, e ambas, contanto que esteja em paz consigo mesmo, necessariamente se harmonizam com ele que tem em si o fundamento para a sua paz" (PICO, 2004, p. 305) (tradução nossa). 12 Pico usa o verbo "reformar" para indicar a atividade da imaginação que liberta o objeto da consciência das "deformidades" da matéria. No entanto, sendo
} 
entre Natureza e espírito se realiza por obra do homem, mas somente quando ele escolhe usar a própria liberdade: o homem que escolhe ser como uma besta ou um vegetal, renunciar à plena humanidade para limitar-se a exprimir somente aquilo que o une aos animais ou às plantas, rompe a ordem natural das coisas e interrompe aquela fusão entre espírito e matéria sobre a qual se funda a harmonia de tudo e a beleza do cosmo. Por isto, não apenas Deus, mas a Natureza e os céus devem vingar-se dele, perseguindo-o e constrangendo-o a viver "como aqueles que rondam em torno da terra e do mar e sempre acabam punidos pelo açoite divino. Estes fulminam e perseguem o céu, a terra, toda a inquebrável justiça da Cidade universal" (PICO, 2004, p. 307). Ao examinar bem, a situação do pecador em Pico não é muito diversa da condição humana descrita no Theogenius: "o homem é inimigo capital do que ele vê e do que ele não vê [...] inimigo da geração humana, inimigo de si mesmo" (ALBERTI, 2014, Theogenius, cit., Livro II).

Escreveu Eugenio Garin (1975, p. 153), “o homem exprime o absurdo e a loucura da vida”, uma loucura gerada da inconsciência de quem "quer navegar o mar e transportar-se, creio, para fora do mundo" (Ibidem). O homem de Theogenius é inimigo de si mesmo e da Natureza na medida em que é "o signo de uma ruptura do ser" (Idem, p. 178), a mesma a quem constitutivamente é exposto o "grande milagre" de Pico, com uma diferença radical: em Pico, a liberdade humana é a brecha que sempre faz passar um pouco de luz sobre a tragédia da existência humana; em Alberti do Theogenius, do Momus e das Intercenales, ao contrário, a dureza do destino humano parece fechar cada espaço de salvação.

a imaginação uma faculdade ainda "material e orgânica" não pode completar esta operação, que se concluirá somente na atividade puramente espiritual do intelecto (PICO, 2004, p. 577). 


\section{Recomposição da ordem}

Como escreveu Eugenio Garin,

[...] destruída a mediação humana entre um céu desprovido de deus e um mundo vazio de qualquer intervenção providencial, restituída à sua miséria real o mortal deus feliz, que coisa resta se não o absurdo de forças cegas, de formas sem rumo, de eventos privados de sentido? (1975, p. 179)

Talvez reste qualquer coisa. Resta o sentido das operações provisórias do arquiteto, justamente porque, consciente do fato de que o homem é "quase sombra de um sonho" e a vida humana uma "brincadeira da Natureza" (ALBERTI, 1986, p. 76), ele deve buscar agir em vista "do menor dano ou da máxima utilidade possível" (ANGELINI, 2007, p. 64). Resta o saber do artífice, que, mais do que o filósofo, pode conhecer e representar a realidade na sua loucura e efemeridade (BRANDÃO, 2010, p. 155 ss). Resta, enfim, a importância da busca da virtude que, mesmo nas páginas mais sombrias de Alberti, permanece como a única perspectiva de sentido possível. A recomposição da ordem natural das coisas, dilacerada tanto em Pico como em Alberti, da hybris e da baixeza do homem, depende, em última análise, justamente da possibilidade de um percurso moral que forme o homem em sua inteireza. O exercício da virtude é, assim, o único caminho possível para recompor a fratura aberta entre o homem e ele mesmo e entre o homem e a Natureza.

Na Intercenale intitulada Fatum et fortuna, Leon Battista Alberti recapitula em forma poética a própria concepção da vida e do homem. De cima de uma "altíssima montanha", 
circundada por um rio "excepcionalmente rápido e cheio de vórtices", descem "inumeráveis multidões de sombras" (ALBERTI, 2003, p. 43), "centelhas de fogo celeste [...] destinadas a tornar-se homens" (Idem, p. 44). O nome do rio é "Vida e Tempo" (Idem, p. 47), e as sombras devem atravessá-lo buscando evitar os penhascos e os perigos. A sua viagem termina apenas quando todas as almas são carregadas pelo rio que representa a morte. Certas sombras tentam atravessar o rio a bordo de cabaças, e à primeira vista parecem ser mais afortunadas do que aquelas que sem ter nada tentam percorrer o rio a nado. $\mathrm{Na}$ realidade, estas cabaças, "sopradas de esplendor e pompa" (Idem, p. 46-48), são riquezas completamente inúteis e destinadas a ficar em pedaços no primeiro penhasco. Mais afortunadas são as sombras que, sem possuir nenhuma riqueza, são obrigadas a aprender a nadar sozinhas. Também os deuses voltam seu afeto e benevolência a elas, porque são aquelas as almas mais "industriosas" e "ativas". Os impérios e as cidades são representados por barcos muito mais seguros, mas nunca fortes o bastante para suportar o impacto com os penhascos mais perigosos. Os magnânimos e os bons cuidam da própria nave, e estas almas "preferem sempre uma nave muito pequena a uma prancha privada" (Idem, p. 50), mas também as melhores naves são destinadas a afundar. Para Alberti, de fato, qualquer ordem social e política é sempre muito frágil para resistir aos perigos do tempo e da fortuna. $\mathrm{Na}$ navegação, todos são impedidos por aqueles que, incapazes de nadar e invejosos, buscam continuamente impedir os outros que o façam. Os avaros, por sua vez, ficam prisioneiros da lama, buscando roubar aqui um barril, ali uma mesa. Apenas os mais sábios atravessam o rio a bordo de pequenas mesas que representam as artes: aqui Alberti não se refere apenas aos 
grandes homens que criaram a própria mesa (os fundadores de uma disciplina ou de uma arte), mas também a quem as fez crescer, aperfeiçoando um campo do saber, a quem conseguiu salvar uma destas mesas dos penhascos e do esquecimento, e, enfim, a quem conseguiu construir "por analogia" novas mesas para oferecer a outros navegantes.

A narrativa poética de Alberti se fecha na definição de Fato entendido como "o curso das coisas na vida humana, que transcorre segundo uma ordem própria” (Idem, p. 54-56), e de Fortuna, que sendo mais ou menos ágil se mantém de certo modo nas mãos do homem ${ }^{13}$ : cada homem, de fato, renunciando às riquezas vãs e refutando o vício, pode escolher aprender a nadar sozinho, não tanto para obter benevolência dos deuses, mas, ainda melhor, para receber a estima dos homens justos.

Nesta intercenale de Alberti, a dialética liberdade-necessidade se articula em uma reflexão a respeito do destino, consciente dos impedimentos que limitam o agir livre do homem, mas aberta à possibilidade de um caminho ético que premia os sábios. A reflexão albertiana sobre a relação entre vida ativa e vida contemplativa articula-se atribuindo a essas duas perspectivas espaços e razões diferentes: ambas têm fundamento em uma dimensão totalmente humana. O homem pode legitimamente abandonar-se à contemplação, na medida em que é lícito tender à serenidade e à paz. Quem escolhe esta via, entretanto, não busca a visão beata de Deus,

\footnotetext{
13 "Fortunam vero illis esse faciliorem animadverti, qui tum in fluvium cecidere, cum iuxta aut integre asserule aut navicula fortassis aliqua aderat. Contra vero fortunam esse duram sensi nobis, qui eo tempore in fluvium corruissemus, quo perpetuo innixu undas nando superare opus sit. Plurimum tamen in rebus humanis prudentiam et industriam valere non ignorabimus" (ALBERTI, 2003, p. 56).
} 
mas quer apenas evitar os tormentos ligados à vida política: a sua virtude consiste no servir de modo diverso à coletividade, acrescentando, por exemplo, o saber no campo das artes e das ciências. Em Alberti, escolhem-se as aporias inerentes à dialética entre liberdade e necessidade porque estão colocadas no plano de interesses comuns, em uma dimensão prática em que o espaço do agir humano coincide com o dever de fazer florescer as melhores obras humanas na plena consciência de sua efemeridade. É precisamente neste espaço que o homem pode operar sem opor-se ao destino e à Natureza, aceitando a ordem e as leis sem resignar-se, mas também sem tentar inutilmente infringi-las, e, assim, pode navegar sobre o rio da vida e do tempo e criar, salvar e acrescentar um saber totalmente humano que na virtude se realiza como síntese de pensamento e Natureza.

Consciente da perfeição da Natureza, da sua ordem e das suas leis, o artífice busca não a violentar, mas sim operar em harmonia com seu curso. É assim que na criação artística, por um instante, pensamento humano e Natureza se harmonizam, compenetrando-se em uma obra que tem toda a fragilidade de uma coisa criada por uma sombra de sonho, mas que tem, junto de si, o esplendor da plena realização do pensamento humano.

A imagem perfeita dos riscos da condição humana em Pico é a "daqueles que giram em torno da terra e do mar e sempre são punidos pela esfera divina” (PICO, 2004, p. 307), mas a ideia de liberdade absoluta tem também uma outra face, de outro modo trágica, mas salvífica. Junto às baixezas que transformam o homem em uma besta, existe a escolha livre do sábio que tende à verdade através de um percurso teorético e moral: teorético porque parte de uma pergunta sobre os 
modos do conhecimento humano e desenvolve-se na formulação de uma ordem diversa de saberes; moral porque é em torno da ideia de homem e virtude que Pico constrói a sua concordia philosophorum, e o faz a partir de uma ideia de filosofia entendida como a única atividade na qual o homem se realiza. Para Pico, a busca da verdade coincide com aquela do bem e do belo, e termina na superação da dialética entre sujeito e objeto: o filósofo indaga com a filosofia natural a Natureza que o circunda, domina os instintos de sua própria Natureza com a filosofia moral e, ao fim, descobre em si, como seu produto, a beleza da ordem das coisas. O aperfeiçoamento ético do homem e o conhecimento da Natureza pressupõem a empresa: o ponto fundamental, entretanto, é que apenas na filosofia os dois aspectos se juntam. O filósofo compreende, como objeto de seu pensamento, o próprio pensamento e o processo de reformulação conceitual através do qual ele reformou a realidade externa, transformando o sensível em ideia, o particular em universal, o objeto externo em conceito $^{14}$. Por isso, o homem que permite apenas seus apetites, o bruto ou o vegetal da Oratio, representa uma fratura entre o mundo sensível e aquele inteligível. Ao contrário, enquanto filósofo, o homem é união e síntese dos dois mundos, é o instrumento através do qual Natureza e pensamento comunicam-se e fundem-se.

\footnotetext{
${ }_{14}$ No Commento o processo do conhecimento humano parte dos "fantasmas" da mente, que provêm necessariamente dos sentidos, mas depois são a imaginação, a razão e o intelecto a levá-los à síntese e a plasmar, por abstração, o objeto da consciência, com uma operação através da qual a mente redescobre dentro de si a ordem de todas as coisas. No Commento, é a passagem do conhecimento legado aos sentidos àquilo puramente intelectual, o momento no qual a mente descobre em si mesma, depois de haver purificado com a imaginação e a razão, o objeto que antes estava na sua frente: "Nesta cognição universal, a alma como em coisa por ela fabricada se deleita [...] e nela a luz da verdadeira beleza, como luz do sol sobre a água, se vê" (PICO, 2004, p. 579).
} 
É na Oratio que Pico descreve o itinerário moral e cognoscitivo que conduz o homem à realização de si mesmo na filosofia:

[...] emulando na terra a vida querubínica - escreve Pico - refreando o ímpeto das paixões com a ciência moral, dissipando a treva da razão com a dialética, purifiquemos a alma limpando-a das sujidades da ignorância e do vício para que os afetos não se desencadeiem cegamente, nem a razão imprudente, algumas vezes delire. $\mathrm{Na}$ alma, portanto, assim recomposta e purificada, difundamos a luz da filosofia natural, levando-a em seguida à perfeição final mediante o conhecimento das coisas divinas (PICO, 2011, p. 65).

Em primeiro lugar, o homem deve aprender a dominar a si mesmo, e é essa a premissa necessária a qualquer outro tipo de conhecimento. A virtude é o domínio do homem sobre si mesmo e é o pensamento que se impõe sobre o corpo e transcende o instinto natural na obediência à lei moral. O conhecimento da Natureza depende desta premissa fundamental: apenas a alma "composta e purificada" pela moral, a alma que impôs a própria lei a si mesma, pode cumprir a mesma operação com a Natureza externa. Conhecimento, domínio de si e investigação da Natureza são possíveis, entretanto, apenas através da dialética, através de um saber que coincide com o próprio desenvolvimento da filosofia. A dialética em Pico serve para "dissipar a treva da razão", é método de análise, obra de esclarecimento conceitual, processo através do qual o pensamento reformula a própria Natureza do homem. Sem o uso correto da razão, o pensamento está destinado ao delírio e à loucura das paixões e, por isso, a outra face da liberdade quase heroica, que permite ao homem escolher o caminho do 
conhecimento, é a amarga consciência das feridas, dos vícios e das dúvidas que caracterizam a vida humana. A filosofia, por um lado, é a cura e o bálsamo para tudo isso, mas, por outro lado, ela se explica e encontra o próprio limite no estado conflituoso que caracteriza o mundo e a Natureza. E é justamente neste contexto que volta novamente em Pico a ideia de natureza como conflito, sempre em referência a Homero e Heráclito:

A dialética acalmará a razão tumultuosamente mortificada entre os contrastes das palavras e dos silogismos capciosos. A filosofia natural acalmará os conflitos da opinião e os dissídios que atormentam, dividem e dilaceram de modos diversos a alma inquieta. Mas acalma-los-á de modo a recordar-nos que a natureza, como disse Heráclito, é gerada da guerra e, por isso, chamada por Homero de luta (PICO, 2011, p. 69).

A partir desta contraposição entre a busca inquieta, que caracteriza a filosofia, e a "paz estável" da teologia, torna-se possível compreender a tensão moral que Pico coloca como a verdadeira tarefa do filósofo. Em primeiro lugar, a filosofia se exercita no confronto de homens com homens, na dimensão pública da disputa, e ela tem o direito de trazer ao embate entre as opiniões humanas "Deus, a natureza e a moral": o embate e o conflito animam a busca filosófica, e sem verdadeiras discussões humanas cada filosofia seria apenas - escreve Pico - "torpemente sonhadora” (PICO, 2004, p. 137). Em segundo lugar, Pico distingue claramente o espaço da razão filosófica e aquele da fé: trata-se de duas dimensões separadas, sujeitas a lógicas diferentes. A filosofia se ocupa do provável e das opiniões humanas, a fé, das verdades indiscutíveis; admitindo-se que existem. Somente distinguindo-as é possível reconhecer a importância de ambas. Caso contrário, não existe filosofia 
e a própria fé vacila. A tarefa do filósofo é aquela de desvelar contradições, reencontrar significados e entrar diretamente na palavra, mas trata-se de uma busca que mantém em si toda a tragicidade do operar sempre provisório e fugidio do arquiteto de Alberti:

Ridícula e sacrílega - escreve Pico - é a nossa temeridade que reivindica o juízo sobre a ordem universal, sobre a sabedoria divina que estende o olho da providência e o raio de sua bondade, mas não à utilidade de um só homem, de uma só família, de uma só cidade, mas àquela de todo o mundo, e não por um século, mas por todos os séculos (PICO, 1946, p. 445).

O tempo é novamente o elemento que condena o homem a um saber e a um agir irremediavelmente frágil. A ordem de todas as coisas, o sentido da história, o porquê das mudanças e do devir: tudo isso ocorre segundo tempos incompreensíveis ao homem. O filósofo de Pico, exatamente como o arquiteto de Alberti, bem sabe que não faria sentido opor-se ao contínuo curso da Natureza ou tentar inutilmente fixar de uma vez por todas as razões e as leis da ordem das coisas. A ambos resta, entretanto, o espaço de um dia, um lapso de tempo finito no qual o filósofo ou o arquiteto podem transformar a loucura das próprias paixões em virtude, o desconhecido movimento das estrelas em conjeturas, os fantasmas da Natureza em produtos do pensamento. Criatura de um dia, sombria e frágil, na consciência de seu ser finito, o homem descobre uma perspectiva sobre o infinito: a partir da própria fraqueza e temporalidade, pode libertar-se do dogma e da aparência, pode abrir-se finalmente à dignidade do caminho moral em direção à sabedoria, na qual realiza-se finalmente como harmonia e síntese de pensamento e Natureza. 


\section{Referências}

ALBERTI, Leon Battista. Opere volgari, a cura di C. Grayson. Bari: Laterza, 1966.

- I libri della famiglia, a cura di Ruggiero Romano e Alberto Tenenti. Torino: Einaudi, 1969.

- Momo o del Principe, a cura di Rino Consolo. Genova: Edizioni Costa e Nolan, 1986.

. De re aedificatoria libri decem, a cura di G. Orlandi e P. Portoghesi. Milano: Il Polifilo, 1989.

Intercenales, a cura di Franco Bacchelli e Luca D’Ascia, premessa di Alberto Tenenti. Bologna: Edizioni Pendragon, 2003.

. Opere. Edizioni La Biblioteca Digitale, 2014.

ANGELINI, Annarita. Larchitettura come "umbra d'un sogno". In: Il pensiero simbolico nella prima età moderna, a cura di A. Angelini e P. Caye. Firenze: Olschki, 2007.

BRANDÃO, Carlos. O filosofo e o pintor: humanismo $e$ anti-humanismo em Leon Battista Alberti. In: "O que nos faz pensar", Cadernos do Departamento de Filosofia da PUC-Rio, n. 27, Maio 2010.

GARIN, Eugenio. Studi su Leon Battista Alberti. In: Rinascite e Rivoluzioni. Roma-Bari: Laterza, 1975. 
GARIN, Eugenio. Il pensiero di Leon Battista Alberti: caratteri e contrasti. In: ALBERTI, Leon Battista. Studi nel V Centenario della morte. Firenze: Sansoni, 1972.

GRAYSON, Cecil. Studi su Leon Battista Alberti, a cura di P. Claut. Firenze: Olschki, 1989.

PICO, Giovanni. Disputationes adversus astrologiam divinatricem, a cura di E. Garin, vol. 2. Firenze: Olschki, 1946; 1952.

. Heptaplus. In: De hominis dignitate, Heptaplus, De Ente et Uno, a cura di E. Garin. Torino: Aragno, 2004. . Discurso sobre a dignidade do Homen. Tradução e apresentação de Maria de Lourdes Sirgado Ganho. Lisboa: Edições 70, 2011.

PÍNDARO. Tutte le opere, a cura di E. Mandruzzato. Milano: Bompiani, 2010. 